\title{
PROPERTIES OF ORGANIC COATINGS CONTAINING PIGMENTS WITH SURFACE MODIFIED WITH A LAYER OF $\mathrm{ZnFe}_{2} \mathrm{O}_{4}$
}

\author{
Kateřina Nechvílová', Andréa Kalendová' \\ 1 Faculty of Chemical Technology, Institute of Chemistry and Technology of Macfromolecular Materials, \\ University of Pardubice, Studentská 95, 53210 Pardubice, Czech Republic, e-mail: Katerina.Nechvilova@ \\ upce.cz; Andrea.Kalendova@upce.cz
}

Received: 2015.10.09

Accepted: 2015.11.14

Published: 2015.12.04

\begin{abstract}
This work is focussed on the properties of organic coatings containing pigments whose surface was chemically coated with zinc ferrite $\left(\mathrm{ZnFe}_{2} \mathrm{O}_{4}\right)$ layer. Four silicate types with different particle shapes were selected as the cores: diatomite, talc, kaolin and wollastonite. The untreated particles exhibit a barrier effect. The aim of this project was to apply the surface treatment approach with a view to enhancing not only the model paint films' anticorrosion properties but also their resistance to physico- mechanical tests pursuant to ISO standards (cupping, bending, impact, adhesion). Other parameters examined included: particle size and morphology, density of the modified pigment, oil consumption, $\mathrm{pH}$, conductivity, and electrochemical properties of the paint film. A solvent-based epoxy-ester resin was used as the binder and also served as the reference material. The pigment volume concentration (PVC) was $1 \%$ and $10 \%$. During the last stage of the experiment, the paint films were exposed to a corrosive environment stimulating seaside conditions or conditions roads treated with rock salt. The accelerated cyclic corrosion test in a neutral salt mist atmosphere was conducted for 864 hours. The results served to ascertain a suitable environment for organic coatings.
\end{abstract}

Keywords: zinc ferrites, silicates, surface protection, organic coatings.

\section{INTRODUCTION}

Organic coatings represent one of many ways to protect objects (not only metallic) from degradation detracting from their performance. This degradation - material corrosion - is nearly always undesirable. Recent research has been focussing on the development of anticorrosion paints that provide better anticorrosion protection than the routinely used materials and, in addition, are reasonably environmentally friendly [1]. The present study was devoted to the properties of organic coatings containing silicon oxide based pigments with the surfaces modified with a chemical layer of zinc ferrite $\left(\mathrm{ZnFe}_{2} \mathrm{O}_{4}\right)$. Zinc ferrite is a crystalline inorganic spinel type pigment. The structure of zinc ferrite can be described by the general formula $\mathrm{AB}_{2} \mathrm{O}_{4}$ where $\mathrm{A}$ and $\mathrm{B}$ are, e.g., $\mathrm{Fe}, \mathrm{Al}, \mathrm{Ba}, \mathrm{Mg}, \mathrm{Zn}, \mathrm{Ni}$, Co or $\mathrm{Ca}$ and where the cations are arranged in octahedral and tetrahedral gaps $[2,3]$. In this particular case, $\mathrm{A}$ was $\mathrm{Zn}^{2+}$ and $\mathrm{B}$ was $\mathrm{Fe}^{3+}$ [4]. Targeted selection of the cations modifying the spinel lattice can be used to change the properties or create new properties of the pigment dispersed in an organic binder [5]. The $\mathrm{ZnFe}_{2} \mathrm{O}_{4}$ spinels are thermally stable [6], exhibit a high covering power, are insoluble $[7,8]$, are resistant to aggressive media [9], and the cost of their preparation is reasonably low [2]. Spinel pigments enhance mechanical strength of the binder through a chemical reaction that produces cationic soaps, thereby reducing their solubility and tendency to saponify on exposure to a corrosive environment where hydroxy ions are created [10]. The objective of this work with zinc ferrite is to slow down or completely inhibit metal corrosion. Metal corrosion is an electrochemical process which can be suppressed by charge transfer aimed 
at avoiding metal degradation. Generally, the corrosion process is promoted, e.g., by chloride ions, which dissolve iron oxides. To inhibit corrosion of a metallic substrate, ferrous ions $\left(\mathrm{Fe}^{2+}\right)$ must be transformed to ferric ions $\left(\mathrm{Fe}^{3+}\right)$, which act as inorganic corrosion inhibitors in the electrochemical process. In this manner it is possible to create a passivation layer which will suppress the cathodic and/or anodic reaction [5, 11]. Depending on the pigment, organic coatings do not act electrochemically only: the also provide barrier [12] or mechanical [13] protection against corrosive environments. The present paper describes the properties of the reasonably well available pigments diatomite, talc, wollastonite and kaolin, each modified with a layer of zinc ferrite on the particle surface. The advantage of this surface treatment is the synergistic effect of barrier protection and the inhibiting reaction in a region unsuitable for the corrosion reaction. A low amount of $\mathrm{ZnFe}_{2} \mathrm{O}_{4}$, can be used for the surface treatment, 16-20 wt.\% of the volume, which is financially beneficial.

The goal of this work was to use the pigment surface treatment to enhance not only the anticorrosion efficiency of model paint films but also their resistance in physico-mechanical tests performed according to CSN ISO standards (cupping, bending, impact, adhesion). The assets of the surfacemodified pigments should also include non-toxicity and the use of traditional natural sources.

\section{EXPERIMENTAL}

\section{Preparation of the surface-treated pigment, specification of the pigment}

The pigment surface treatment procedure was conducted in laboratory conditions. An amount of $50 \mathrm{~g}$ of the pigment was suspended in 4 litres of distilled water acidified with $5 \mathrm{ml}$ of $\mathrm{H}_{2} \mathrm{SO}_{4}$, and $\mathrm{ZnSO}_{4} \cdot \mathrm{H}_{2} \mathrm{O}, \mathrm{Fe}_{2}\left(\mathrm{SO}_{4}\right)_{3} \cdot 6 \mathrm{H}_{2} \mathrm{O}$ and urea were added. The system was heated to boil and $\mathrm{pH}$ was measured during the reaction. The reaction was terminated on attaining $\mathrm{pH} 8$. The product was decanted, filtered out, rinsed with water, and dried at $110^{\circ} \mathrm{C}$, and the dry material was annealed at $800{ }^{\circ} \mathrm{C}$ for 2 hours. The pigments so prepared were specified as stipulated in EN ISO 787-10 and EN ISO 787-5, and the critical pigment volume concentration (CPVC) was determined. The particle shape was examined on a JEOL - JSM 5600 electron microscope.

\section{Paint formulation and preparation}

A solvent-type epoxy-ester resin (WorléeDur D46, Worlée Chemie, Germany) was used as the coating material binder. The model paints were prepared by adding the pigment to the binder and homogenizing the system. The pigment volume concentration (PVC) in the paint was $1 \%$ and $10 \%$. The paints were pre-prepared on a dissolver and dispersed in a bead mill at $3000 \mathrm{rpm}$ for 45 minutes. Nuodex Combi (Sigma-Aldrich) was added (0.1 wt.\%) as a siccative. The paints were applied to glass and steel panels. The non-pigmented epoxy-ester resin served as the reference material for comparing the properties of the paints.

\section{Relative surface hardness measured on a pendulum apparatus}

Surface hardness relative to a glass standard (\%) was measured on a Persoz type pendulum apparatus as per CSN 673076 during 120 days.
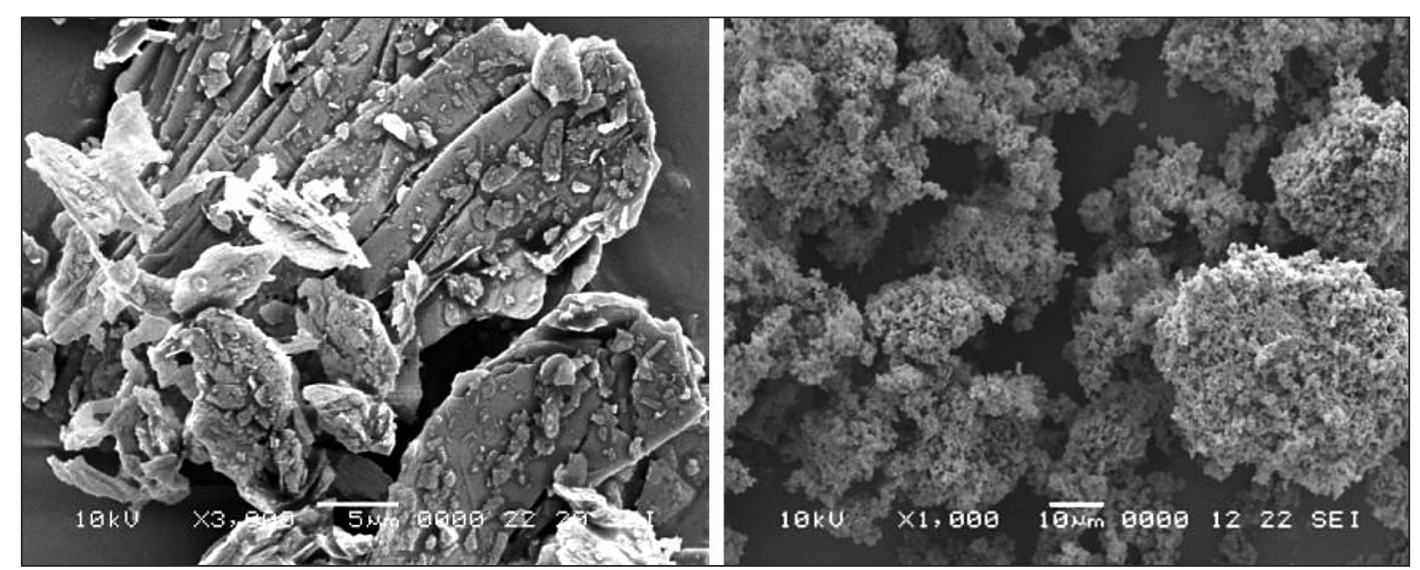

Fig. 1. An untreated talc particle, magnification $3000 \mid \times(\mathrm{left})$; a talc particle with its surface treated with a chemical layer of $\mathrm{ZnFe}_{2} \mathrm{O}_{4}$, magnification $10001 \times$ (right) 


\section{Physico-mechanical tests}

The physico-mechanical properties of the paint films were determined by subjecting the films to mechanical and destructive stress according to ISO standards 2409, 6272, 1519, and 1520 .

\section{Determination of $\mathrm{pH}$ and specific electric conductivity of and corrosion losses in aqueous extracts}

The $\mathrm{pH}$ and specific electric conductivities of $10 \%$ aqueous extracts of the loose paint films were measured as specified in EN ISO 789-9 and EN ISO 787-14 during 4 weeks. The suspension was filtered, and a pre-cleaned and pre-weighed steel panel was submerged in the aqueous extract. The panel was removed from the extract after 10 days and the weight loss due to corrosion $\left(\mathrm{K}_{\mathrm{m}}\right)$ was determined.

\section{Accelerated corrosion test in an $\mathrm{NaCl}$ mist (EN ISO 92 27)}

The corrosion test was performed on steel panels $152 \times 102 \times 0.8 \mathrm{~mm}$ size, coated with the paint films. A test cut $7 \mathrm{~cm}$ long was made through each paint film. The panels were exposed to the neutral salt mist / condensed moisture environment during 864 hours, and the corrosion effects were evaluated as per EN ISO 4628-2 to 4628-5 after terminating the exposure. The parameters measured included blistering on the paint film surface (ASTM D 714-78), degree of metal corrosion on the test cut (ASTM D 1654-92) and degree of corrosion of the metal surface (ASTM D 610-85).

\section{Electrochemical method}

Electrochemical examination consisted in linear polarisation measurements using a cell with a reference electrode (SCE), a Pt cathode, and the sample as the working electrode (anode). A $3.5 \% \mathrm{NaCl}$ solution constituted the working medium. The samples were polarised from $-10 \mathrm{mV} / \mathrm{EOC}$ to $+10 \mathrm{mV} / \mathrm{EOC}$ at 0.166 $\mathrm{mV} / \mathrm{s}$. The parameters measured for each paint included the spontaneous corrosion potential $\left(E_{\text {corr }}\right)$, current density $\left(I_{\text {corr }}\right)$, and polarisation resistance $\left(R_{\mathrm{p}}\right)$. The corrosion rate $\left(v_{\text {corr }}\right)$ was calculated.

\section{RESULTS AND DISCUSSION}

Model paints containing $\mathrm{SiO}_{2}$ based pigments whose surface had or had not been modified with a layer of $\mathrm{ZnFe}_{2} \mathrm{O}_{4}$ were prepared. The pigment volume concentrations were $1 \%$ and $10 \%$. A solvent-based epoxy-ester resins was used as a binder, and when containing no pigment, also as the reference material. The physico-mechanical and anticorrosion properties of the paint films were examined. The results are listed in Table 1.

Relative surface hardness (RSH) of the films was measured during 120 days. This parameter increased (with some exceptions) also for films with pigments that on their own (no surface treatment) are rather soft, such as talc. Generally, surface hardness is increased by the presence of the zinc ferrite layer, particularly at $\mathrm{PVC}=10 \%$. The tearing-off force required to detach the paint film (or a part of it) from the substrate increases as well. The situation is opposite with talc: surfaceuntreated talc exhibits a very good particle adhesion both to the resin and to the substrate metal. The force required to tear off the epoxy-ester resin was $235 \mathrm{~N}$, and it was lower if the pigment was present. The overall physico-mechanical resistance (OPMR) of the paint film was $100 \%$, only the paint film with talc as the pigment (film thickness $0.5 \mathrm{~mm}$ ) did not attain the maximum value in the cupping test on the Erichsen instrument; the paint film, though, was no less efficient, actually it was more elastic. The $\mathrm{pH}$ and specific electric conductivities of aqueous extracts of the loose paint films were measured during 28 days.

The suspensions were filtered on day 21 , and clean and pre-weighed steel panels were submerged in them and left there for 10 days. Subsequently, the panels were removed, rinsed and weighed to determine the corrosion losses $\left(K_{m}\right)$ relative to a blank, i.e. redistilled water; RW: pH 5.29-5.79. Submersion of the panels brought about $\mathrm{pH}$ increase by $1-2$ units. The $\mathrm{pH}$ shift was due to the effect of the pigment itself and by the effect of the surface treatment, owing to which the system had a tendency to saponification. Although the $\mathrm{pH}$ remained in the acid region, the effect of the resin itself, the $\mathrm{pH}$ of the pigment powders was in the range of 7.56-8.49.

Specific electric conductivity (S) increased with electron exchange in the pigment-paintsubstrate system. The paint films were exposed to the effect of condensed moisture with salt mist during 864 hours. The apparent corrosion effects 
Table 1. Properties of the test paint films

\begin{tabular}{|c|c|c|c|c|c|c|c|c|c|c|c|c|c|c|}
\hline Sp. & PVC & $\begin{array}{l}\text { RSH } \\
{[\%]}\end{array}$ & $\begin{array}{c}\text { OPMR } \\
{[\%]}\end{array}$ & $\begin{array}{c}\text { Fmax } \\
{[\mathrm{N}]}\end{array}$ & $\begin{array}{c}\mathrm{pH} \\
0 \text { day }\end{array}$ & $\begin{array}{c}\mathrm{pH} \\
21 \text { day }\end{array}$ & $\begin{array}{c}\mathrm{pH} \\
28 \text { day } \\
\end{array}$ & $\begin{array}{l}\text { S } 0 \text { day } \\
{[\mu \mathrm{S} / \mathrm{cm}]}\end{array}$ & $\begin{array}{l}\text { S 21 day } \\
{[\mu \mathrm{S} / \mathrm{cm}]}\end{array}$ & $\begin{array}{l}\text { S } 28 \text { day } \\
{[\mu \mathrm{S} / \mathrm{cm}]}\end{array}$ & $\mathrm{K}_{\mathrm{m}}[\%]$ & $\begin{array}{l}E_{\text {corr }} \\
{[\mathrm{mV}]}\end{array}$ & $\mathrm{R}_{\mathrm{p}}[\Omega]$ & $\begin{array}{c}\mathrm{NaCl} \\
{[\%]}\end{array}$ \\
\hline \multicolumn{15}{|c|}{ Non-modified pigments } \\
\hline \multirow{2}{*}{ D } & 1 & 32 & 100 & 110 & 3.41 & 3.18 & 4.42 & 133 & 207 & 197 & 48.8 & -280 & $4.86 \cdot 10+5$ & 65 \\
\hline & 10 & 33 & 100 & 114 & 3.65 & 3.48 & 5.08 & 85 & 138 & 214 & 87.8 & -395 & $1.64 \cdot 10+5$ & 86 \\
\hline \multirow{2}{*}{$\mathrm{T}$} & 1 & 31 & 100 & 178 & 3.63 & 3.39 & 4.83 & 93 & 153 & 219 & 63.4 & -458 & $4.40 \cdot 10+4$ & 63 \\
\hline & 10 & 33 & 100 & 302 & 3.74 & 3.43 & 4.09 & 61 & 116 & 131 & 51.2 & -155 & $2.45 \cdot 10+4$ & 94 \\
\hline \multirow{2}{*}{ K } & 1 & 33 & 100 & 157 & 3.54 & 3.22 & 4.27 & 102 & 181 & 171 & 17.1 & -277 & $1.12 \cdot 10+5$ & 66 \\
\hline & 10 & 35 & 100 & 160 & 3.53 & 3.26 & 4.15 & 103 & 179 & 172 & 52.3 & -368 & $8.51 \cdot 10+3$ & 67 \\
\hline \multirow{2}{*}{ W } & 1 & 36 & 100 & 180 & 3.85 & 4.01 & 5.07 & 48 & 61 & 79 & 36.6 & -652 & $1.17 \cdot 10+5$ & 17 \\
\hline & 10 & 36 & 100 & 159 & 6.04 & 6.36 & 5.73 & 46 & 111 & 105 & 9.76 & -584 & $1.47 \cdot 10+4$ & 75 \\
\hline \multicolumn{15}{|c|}{ Surface modified pigments with layer $\mathrm{ZnFe}_{2} \mathrm{O}_{4}$} \\
\hline \multirow{2}{*}{ D } & 1 & 36 & 100 & 150 & 3.57 & 4.81 & 4.64 & 103 & 166 & 146 & 48.8 & -136 & $1.85 \cdot 10+4$ & 90 \\
\hline & 10 & 33 & 100 & 178 & 3.89 & 3.70 & 4.93 & 75 & 151 & 183 & 65.9 & -293 & $1.41 \cdot 10+5$ & 47 \\
\hline \multirow{2}{*}{$\mathrm{M}$} & 1 & 36 & 100 & 127 & 3.76 & 3.47 & 5.23 & 62 & 119 & 129 & 70.7 & -206 & $1.64 \cdot 10+6$ & 85 \\
\hline & 10 & 34 & 98.8 & 195 & 4.21 & 3.38 & 5.43 & 36 & 70 & 104 & 137 & -208 & $5.16 \cdot 10+4$ & 69 \\
\hline \multirow{2}{*}{$K$} & 1 & 37 & 100 & 139 & 3.61 & 5.10 & 4.50 & 168 & 185 & 350 & 65.9 & -132 & $1.64 \cdot 10+6$ & 61 \\
\hline & 10 & 36 & 100 & 189 & 3.70 & 4.02 & 4.91 & 65 & 138 & 138 & 65.9 & -225 & $1.02 \cdot 10+6$ & 80 \\
\hline \multirow{2}{*}{ W } & 1 & 35 & 100 & 141 & 3.50 & 3.36 & 4.01 & 13 & 245 & 228 & 36.6 & -351 & $9.28 \cdot 10+4$ & 74 \\
\hline & 10 & 29 & 100 & 168 & 4.03 & 3.39 & 5.38 & 131 & 149 & 12 & 156 & -146 & $1.10 \cdot 10+6$ & 84 \\
\hline \multicolumn{15}{|c|}{ Blank sample } \\
\hline$E$ & $x$ & 33 & 100 & 235 & 3.42 & 3.38 & 3.30 & 92 & 195 & 232 & 88 & -586 & $4.41 \cdot 10+3$ & 50 \\
\hline RW & $x$ & - & - & - & 5.29 & 5.87 & 5.79 & 2 & 2 & 82 & 100 & - & - & - \\
\hline
\end{tabular}

Notes: $\mathrm{D}$ - diatomite; T - talc; $\mathrm{K}$ - kaolin; $\mathrm{W}$ - wollastonite; E - epoxy-ester resin; RW - redistilled water.

were evaluated and the overall anticorrosion efficiency of the system was calculated (see Table 1, $\mathrm{NaCl}[\%]$ ). Talc at $\mathrm{PVC}=10 \%$ exhibited the best results among the untreated pigments, and diatomite at $\mathrm{PVC}=1 \%$ provided the best results among the pigments whose surface had been treated with $\mathrm{ZnFe}_{2} \mathrm{O}_{4}$. Although not all surface treatments led to higher corrosion protection values, all the surface-treated pigments at either of the two PVC levels reduced appreciably corrosion of the steel panel surface because corrosive medium penetration to the substrate was prevented or hindered by the protective film. The overall anticorrosion protection values agreed well with the electrochemical measurement results: a lower degree of corrosion protection was accompanied by a lower $E_{\text {corr }}$ value. For instance, wollastonite at $\mathrm{PVC}=1 \%$ exhibited $E_{\text {corr }}=-652 \mathrm{mV}$, and the corrosion test resulted in many blisters on the paint film surface and appreciable metal corrosion in the cut. The trend was opposite with the polarisation resistance $\left(R_{\mathrm{p}}\right)$ : the higher the order of magnitude, the better the anticorrosion protection of the metal; and surface treatment of the pigments brought about increase by $1-2$ orders of magnitude.

\section{CONCLUSIONS}

Paints containing pigments whose surface had been chemically modified with a zinc ferrite layer were studied. The paint films exhibited higher relative surface hardness and better physico-mechanical properties. The anticorrosion efficiency improvement was associated with a shift of the spontaneous corrosion potential to values slowing down corrosion of the metal; the polarisation resistance values were also consistent with the corrosion protection efficiency trend. The samples were resistant to a salt mist environment for the 864 hours of the test. so the paints are categorised as C5-I according to ISO 12500 (medium degree-resistance to enhanced salinity environment).

\section{REFERENCES}

1. Singh S., Kumar N., Bhargava R., Sahni M., Sung K., Jung J.H. Magnatodielectric effect in $\mathrm{BaTiO}_{3} /$ $\mathrm{ZnFe}_{2} \mathrm{O}_{4}$ core/shell nanoparticles. Journal of Alloys and Compounds, 587, 2014, 437-441. 
2. Cunha I.T. et al. Catalytic oxidation of aqueous sulfide in the presence of ferrites $\left(\mathrm{MFe}_{2} \mathrm{O}_{4}, \mathrm{M}=\mathrm{Fe}\right.$, $\mathrm{Cu}, \mathrm{Co}$ ). Catal. Today, 2015 (article in press).

3. Miszcyk A., Darowicki K. Study of antocorrosion and microwave absorption properties of NiZn ferrite pigments. Anti-Corrosion Methods and Materials, 58, 2011, 13-21.

4. Kalendová A., Ryšánek P., Nechvílová K. Investigation of the anticorrosion efficiency of ferrites $\mathrm{Mg}_{1-\mathrm{x}} \mathrm{ZnFe}_{2} \mathrm{O}_{4}$ with different particle morphology and chemical composition in epoxy-ester resin-based coatings. Progress in Organic Coatings, 86, 2015, 147-163.

5. Chaudhry A.U., Mittal V., Mishra B. Nano nickel ferrite $\left(\mathrm{NiFe}_{2} \mathrm{O}_{4}\right)$ as anti-corrosion pigment for API 5L X-80 steel: An electrochemical study in acidic and saline media. Dyes snd Pigments, 158, 2015, 18-26.

6. Liu Y., Wei S., Tong H., Tian H., Liu M. Corrosion behavior of marnetic ferrite coating prepares by plasma spraying. Materials Research Bulletin, 60, 2014, 359-366.

7. Chromy L., Kaminska E. Non-toxic anticorrosive pigments. Progress in Organic Coatings, 18, 1990, 319-324.
8. Dondi M., Zanelli C., Ardit M., Cruciani G., Mantovani L., Tribaudino M., Andreozzi G.B., Ni-free. black ceramic pigments based on $\mathrm{Co}-\mathrm{Cr}-\mathrm{Fe}-\mathrm{Mn}$ spinels: A reappraisal of crystal structure. color and technological behavior. Ceramics International, 39, 2013, 9533-9547.

9. Kalendová A. Alkalisong and neutralising effects of anticorrosive pigments containing $\mathrm{Zn}, \mathrm{Mg}, \mathrm{Ca}$ and $\mathrm{Sr}$ catoins. Progress in Organic Coatings, 38, 2000, 199-206.

10. Brodinová J., Stejskal J., Kalendová A., Investigation of ferrites properties with polyaniline layer in anticorrosive pigments. Journal of Physics and Chemistry of Solids, 68, 2007, 1091-1095.

11. Hayyan M., Sameh S.A., Hayyan A., Al Nashef I.M. Utilizing of sodium nitrate as inhibitor for protection of carbon steel in salt solution. International Journal of Electrochemical Science, 7, 2012, 6941-6950.

12. Zhu Y.D., Allen G.C., Adams J.M., Gittins D.I., Hooper J.J., Skuse D.R. Barrier properties of latex/kaolin coatings. Polymer Chemistry, 16, 2013, 4386-4395.

13. Behler K.D., Stravato A., Mochalin V., Korneva G., Yushin G., Gofotsi Y. Nanodiamond-Polyymer Composite Fibres and Coating, ACS Nano, 3, 2009, 363-369. 